doi http://dx.doi.org/10.18542/rmi.v13i21.9545

\title{
OS TRAÇADOS DA CIDADE: A BELÉM DA PRIMEIRA METADE DO SÉCULO XX
}

\author{
THE TRACES OF THE CITY: \\ THE BEAUTY OF THE FIRST HALF OF THE 20TH CENTURY
}

Tatiane do Socorro Correa TEIXEIRA ${ }^{1}$ Pontifícia Universidade Católica de São Paulo ${ }^{2}$

Resumo: O presente artigo visa compreender acerca dos traçados da cidade de Belém entre as décadas de 40 e 50. Objetiva apresentar os lugares de lazer existentes na cidade, o espaço urbano da capital, constituído por um território central, moderno, marcado pelos resquícios da Belle Époque, pelos grandes clubes carnavalescos e territórios com caracterizações depreciativas. Belém emerge como uma trama na qual os fios se intercruzam pelas relações sociais, pelas práticas culturais, sendo uma cidade conectada por fluxos e refluxos de pessoas cotidianamente, que tem nas suas manifestações culturais, a exemplo do carnaval, um marco nos bairros e, consequentemente, na cidade. Portanto, essa multiplicidade de espaços do carnaval belenense comporta as transformações pelas quais Belém passou no final do XIX para o século XX. Assim, estamos discutindo Cidade na perspectiva de Le Goff (1988), Ferrara (1999), Avelino (2009), Arantes (1999), Correa (2010).

Palavras-chave: Cidade. Belém. Lazer.

\begin{abstract}
This article aims to understand the traces of the city of Belem between the 40s and $50 \mathrm{~s}$. It intends to present the existing leisure places in the city, the urban space of the capital, constituted by a central, modern territory, marked by the remnants of the Belle Époque, by the big carnival clubs and territories with derogatory characterizations. Belém emerges as a plot where the threads are intertwined by social relations, cultural practices, being a city connected by flows and refluxes of people on a daily basis, which has in its cultural manifestations, like the carnival, a landmark in the neighborhoods and, consequently, in the city. Therefore, this multiplicity of spaces in the carnival of Belém includes the transformations that Belem underwent at the end of the 19th to the 20th century. Thus, we are discussing City from the perspective of Le Goff (1988), Ferrara (1999), Avelino (2009), Arantes (1999), Correa (2010).
\end{abstract}

Keywords: City. Belém. Leisure.

\footnotetext{
${ }^{1}$ E-mail: tatyluzia@yahoo.com.br

${ }^{2}$ Em decorrência do Mestrado em História Social (Pesquisa financiada pela CAPES)
} 
As crônicas publicadas pela imprensa belenense entre as décadas de 30 e 40 dizem muito acerca do que as elites pensavam sobre os territórios belenenses e seus habitantes, apresentando inclusive um espaço urbano da capital fragmentado, constituído por um território central, moderno, marcado pelos resquícios da Belle Époque, pelos grandes clubes carnavalescos e territórios com caracterizações depreciativas. Isso nos leva a pensar as diferentes significações que participar do carnaval poderia ter para cada folião dos variados espaços existentes em Belém naquele momento. Muitos membros da elite belenense, por exemplo, viam nos clubes um espaço propício para expor seu status social. Já alguns foliões frequentadores das folias públicas viam nestas um espaço de entretenimento e lazer. Logo, analisar esses territórios é significativo e é em torno dessas abordagens que este artigo discorre.

No entanto, para entender Belém é fundamental compreender qual Amazônia é essa na qual a cidade está inserida como uma de suas principais capitais. Para esse entendimento trazemos a abordagem do historiador Serge Gruzinski, em sua obra Pensamento mestiço, na qual disserta sobre o espaço amazônico, focalizando espacialidade, territorialidade e historicidade na Amazônia.

Seu trabalho atua na contramão do que há séculos a historiografia vem produzindo sobre essa parte do país, apresentando questões para se pensar a Amazônia, desconstruindo a imagem de que se tornou comum região selvagem e isolada do mundo. Segundo o autor, a imensa floresta "é um dos reservatórios onde há muito tempo se alimenta nossa sede de exotismo e de pureza”, tecendo críticas às construções de imaginários sobre a Amazônia que se tornaram clichês: o espaço primitivo, espaço da pureza, o espaço de um ontem esquecido, vazio demográfico, floresta selvagem, isolamento. Gruzinski alerta-nos sobre esses clichês para podermos pensar a Amazônia como um espaço da contemporaneidade, seja ontem, seja hoje.

De acordo com o autor, estudiosos que pensam naquela perspectiva não observaram as mudanças históricas e pré-históricas que as populações amazônicas conheceram, as interações entre os povos, vendo-os, por isso, como sociedades imóveis na tradição. Não perceberam, por exemplo, que a elite indígena, desde o século XVI, estabelecia relações políticas, sem ingenuidade, com os brancos que estavam penetrando no espaço amazônico. Essas relações perpassaram o século XVI e permitiram às elites indígenas realizarem interferências significativas na constituição da história desse lugar.

Assim, a Amazônia não pode ser pensada como uma região desatrelada das demais deste país, ou como uma parte do país que destoa do ritmo do conjunto. Deve ser pensada como constituída de dinamicidade, contemporaneidade, marcada por relações sociais, econômicas, comerciais, desde o século XVI. Por isso este traçado da cidade pensa a Amazônia na perspectiva de espaço da 
contemporaneidade, refletida não "fora do tempo", como tantas vezes buscou-se explicar, mas no tempo, sendo mais um caminho na tentativa de conhecer um pouco mais da Amazônia brasileira.

No dia 14 de agosto, o texto de abertura da revista Pará Ilustrado falou de Belém enquanto uma cidade comunicativa, que encanta seus moradores acostumados com seu semblante, atrativo para turistas com seus múltiplos interesses, "Belém é alegre risonha e comunicativa. Como as pessoas da cidade, tem ar, um aspecto, um semblante que a define. Todos os viajantes e turistas são acordes em que a fisionomia de nossa capital lhe atrai o encanto particular" (Revista Pará Ilustrado, 1943, p. 3).

A matéria atua na construção de um retrato de capital estabelecida nas primeiras décadas do século XX, apenas um olhar sobre esse caleidoscópio que era a cidade, onde um bom observador poderia encontrar uma multiplicidade de combinações de imagens. Sendo palco de representações (FLÓRIO; AVELINO, 2009, p. 292), onde se desenrolam tramas, tensões, alegrias, lutas constituindo o cotidiano da humanidade, esta cidade é sinônimo de sociabilidade (LE GOFF, 1988, p. 119).

Nesse sentido, entendemos cidade, a partir das abordagens de Lucrécia Ferrara (1999, p. 33), como um conjunto de manifestações traduzidas nas relações entre as pessoas, nas expressões culturais, na multidão, inclusive na pobreza e na miséria, constituindo-se um aglomerado de signos e significados. Entendemos Belém nestes termos, compreendendo a cidade a partir de suas múltiplas manifestações culturais, enfocando cada bairro como se fossem cidades dentro de uma cidade.

Logo, Belém emerge como uma trama na qual os fios se intercruzam pelas relações sociais, pelas práticas culturais, sendo uma cidade conectada por fluxos e refluxos de pessoas cotidianamente, que tem nas suas manifestações culturais, a exemplo do carnaval, um marco nos bairros e, consequentemente, na cidade; seja na região central - como o bairro da Cidade Velha -, seja nos bairros suburbanos - a exemplo do bairro Jurunas. Nesses bairros, ocorriam vários festejos populares desde longa data no Pará, como, por exemplo, o carnaval; desde (pelo menos) meados do século XVII é possível encontrar relatos em jornais, revistas e crônicas, sobre a festa carnavalesca belenense (OLIVEIRA, 2006, p. 13).

Habitar a cidade, ou seja, agir sobre o espaço urbano através do ato de vivenciá-lo, é realizado de diversas formas e por diferentes sujeitos que determinam as funções e os sentidos desse espaço e, inclusive, estabelecem poder sobre ele. Ao discutir espaço nesta dissertação, estamos discutindo na perspectiva de Antônio Arantes, pensando o espaço enquanto espaço vivido, o espaço como uma referência significativa para os sujeitos que nele vivem, não sendo pensado com sentido unívoco, portador de fronteiras rígidas ou grupos sociais impermeáveis. Em sua obra Paisagens paulistanas, o autor explora a construção social do espaço público, investigando os processos por meio dos quais as 
fronteiras simbólicas se formam e se reconfiguram, seu grau de permeabilidade e fluidez, suas referências de tempo-espaço (ARANTES, 1999, p. 10).

Esses aspectos assinalados por Arantes permitiram pensar o espaço urbano de Belém, compreendendo "as fronteiras simbólicas que separam, aproximam, nivelam, hierarquizam ou, numa palavra, ordenam as categorias e os grupos em suas múltiplas relações” (ARANTES,1999, p. 106). Vislumbramos a cidade de Belém nesta perspectiva, como um agregado de tensões e conflitos, marcado por fronteiras simbólicas onde as festas também determinam uma utilização diferente do espaço urbano. A festa recria o espaço urbano e permite repensá-lo. E essa escolha não se ocorre de forma aleatória, não em qualquer lugar, não em qualquer direção. Suas ações, seja a festa de elite, seja a festa das camadas populares, são repletas de intencionalidades determinantes no sentido e justificativas da própria existência da festa.

No entanto, essa multiplicidade de espaços do carnaval belenense comporta as transformações pela qual Belém passou no final do XIX para o século XX e a constituição dos mesmos. Uma vez que a cidade passava por modificações, redefinia-se e trazia novos hábitos e costumes à população belenense, sendo essas transformações significativas no entendimento de como, neste momento, criaram-se novos lugares de sociabilidade da elite belenense e das classes populares em Belém.

De acordo com a historiografia existente sobre o tema, Belém experimentava um processo de urbanização advinda principalmente do papel que a cidade desempenhou como principal porto de escoamento da borracha durante seu período áureo, possibilitando uma redefinição de seu território, onde o intendente municipal Antônio Lemos ${ }^{3}$ emergiu como agente patrocinador da modernização ${ }^{4}$.

Atrelada às transformações urbanísticas são notórias as transformações culturais pela qual a cidade passou, uma vez que, entre os objetivos da modernização, incluía-se a modificação de hábitos e costumes da população. Assim, segundo Correa (2010, p. 51), novos hábitos e costumes foram incorporados à sociedade que buscava ser moderna, desenhando dessa forma um novo modo de vida, com bares e cafés constituindo um novo ritmo à cidade 5 .

\footnotetext{
${ }^{3}$ De acordo com Maria de Nazaré Sarges, um número significativo de historiadores paraenses associa as transformações ocorridas em Belém no período áureo da economia gomífera e, consequentemente, as transformações urbanas ocorridas no espaço belenense, à capacidade administrativa de Antônio Lemos. SARGES, Maria de Nazaré. Belém, a Urbe das riquezas. In: Belém. Riquezas produzindo a Belle Époque (1870-1912), Belém: Paka-Tatu, 2002, p. 133.

${ }^{4}$ Nesse momento, segundo Sarges (2002, p. 13) foi necessário transformar o espaço urbano belenense, primeiro em virtude da grande leva de imigrantes que impactou a cidade com um crescimento populacional significativo, segundo porque Belém experimentava um desenvolvimento econômico em decorrência do auge da borracha na Amazônia, onde o espaço da cidade tinha que atender aos interesses de uma classe em ascensão. Logo, Belém teve que adequar-se às novas exigências, para assim atender as transformações do capital oriundo da borracha e, principalmente, para facilitar o escoamento da produção.

${ }^{5}$ A abordagem de Correa é singular no sentido de apresentar como, apesar da modernização da cidade, alguns espaços continuaram com traços caracteristicamente rurais, principalmente os bairros do Guamá, Jurunas, Umarizal e Marco, uma
} 
Esse novo modo de vida perpassava inclusive o campo do lazer, onde as elites belenenses estabeleciam seus espaços, os teatros, ambientes de distinção e de sociabilidade desses grupos, buscando se aproximar do universo europeu. Logo, cassinos e clubes tornaram-se exclusivos de grupos mais proeminentes, que podiam pagar pela diversão, reunindo-se em várias ocasiões, inclusive no carnaval, para se divertirem. E é justamente nesse momento que surgem os principais clubes carnavalescos da elite belenense, principalmente no início do século XX. Dentre eles estão os clubes da Assembleia Paraense, da Tuna, do Paysandu, do Clube do Remo e do Palace Cassino. Estes foram criados para atender uma parcela específica da cidade, a elite belenense, detentora de meios para pagar e se divertir nesses salões, seja nos dias de folia, seja nas demais datas comemorativas em que os clubes abriam as portas para receber seus convidados.

Esses clubes formaram-se ao longo do final do século XIX e início do XX nos bairros centrais da cidade, principalmente na Avenida Nazaré e ao redor da Praça da República, constituindo-se espaços de folia, redes de sociabilidade da elite $^{6}$. Decorrido esse período, mais especificamente entre os anos de 1920 e 1930, o Pará ainda sentia o efeito da crise da borracha que levou ao declínio a economia paraense. Todavia, a cidade continuava crescendo, aumentavam os bairros periféricos em população e tamanho, novas ruas e avenidas surgiam. No âmbito cultural, a cidade continuava sendo palco de múltiplas manifestações culturais nos vários bairros, diversas práticas produzidas por homens e mulheres que se apropriavam da cidade e compunham lugares próprios de lazer e, por que não dizer, de folia. Nesse momento, a cidade possuía vários locais para a diversão carnavalesca, desde o mais requintado até o mais popular.

Nas décadas de 30 e 40, Belém era uma cidade com aspectos diferentes dos primeiros anos do século XX, a bonança em decorrência da borracha havia passado, mas os resquícios dessa bela época ainda eram rememorados pela imprensa ao se reportar aos traçados da cidade em 1940. Os jornais do período trazem esses traços, Belém como "a linda cidade das mangueiras, como uma cidade que se reveste garridamente de prédios, os mais elegantes e suntuosos, quer de iniciativa governamental, quer de iniciativa particular" (Jornal Folha Vespertina, 1942, p. 1). Uma cidade que se modificava,

\footnotetext{
vez que o programa de modernização de Antônio Lemos estava delimitado à área central da cidade. A esses espaços, a intencionalidade do administrador era disciplinar, moralizar o comportamento de seus grupos. Logo, o processo de modernização incluía remodelar tanto a cidade quanto os comportamentos das classes populares para sanar o atraso ocasionado pela herança escravista. Por isso, muitas práticas populares foram combatidas em nome do projeto modernizador, afastando-se práticas advindas de tradições africanas e indígenas, para dar lugar a outras, europeias.

${ }^{6}$ De acordo com Maria de Nazaré Sarges, o final do século XIX e início do século XX foi um marco para o desenvolvimento econômico, urbanístico e cultural de Belém. A cidade havia se transformado em metrópole, buscava uma similaridade com as tendências parisienses, imitando-a nos hábitos e costumes. Entretanto, apesar de apresentar uma rica economia, o que se evidenciava era uma cidade marcada pela dicotomia entre a área central, moderna, europeizada e as áreas suburbanas, pobres e tipicamente rurais.
} 
crescia em virtude de seu aumento populacional, como se observa nas palavras de José Godinho Ferreira, no texto intitulado "Movimento de regeneração social":

[...] A construção de diversos postos de saúde pública, de alguns mercados e construções de outros, que necessitavam de melhoramento adequado ao aumento da população. Afora essa, foram feitas modificações na principal repartição policial e erigidos postos policiais nos subúrbios da cidade (Jornal Folha Vespertina, 22 de janeiro de 1942, p. 1).

Esses traços da cidade apresentados por José Ferreira caracterizam apenas uma parte de Belém, a região central. Como abordamos anteriormente, foi a região que mais recebeu investimentos, ou modernização, desde a Belle Époque. Ressalta-se que nos subúrbios da cidade ocorreu a construção de repartições policiais, mas não houve construção de prédios, melhoramentos estruturais, como na área central. O jornal traz apenas uma imagem das múltiplas imagens da cidade, nas palavras de Lucrécia Ferrara (1999, p. 202), traz a imagem daquilo que desperta nossa percepção no cotidiano da vida, e a identificamos como urbana: a construção de prédios, mercados, postos de saúde, constituindo-se no cenário cultural da rotina do povo belenense. Na realidade, a Belém dos anos 30 e 40, tal como a da Belle Époque, não estendia os benefícios da modernidade aos populares, uma vez que atendia apenas aos interesses de grupos elitizados, por isso o melhoramento de algumas áreas em detrimento de outras.

Os bairros, apresentados em processo de transformação pelo jornal, correspondem ao primeiro e segundo distrito da cidade de Belém, formados pelo centro comercial, assim como pela área portuária, onde estavam localizadas as principais praças, os largos, os maiores pontos de lazer da cidade. Nestes locais havia uma preocupação maior com embelezamento e lazer, diferente dos demais distritos onde existiam poucos lugares de diversão e descanso. Nos distritos onde estavam localizados os bairros mais elegantes da cidade, como o Nazaré, a Avenida Independência e São Jerônimo encontravam-se residências, mansões arborizadas, "as artérias elegantes de nossa cidade”, conforme destaca a revista $A$ Semana, de 23 de março de 1939.

O que evidenciamos é que o período da Belle Époque tornou-se marco na história belenense, por isso a tentativa de criar uma imagem da cidade na década de 40 estabelecendo vínculos com esse período. Logo, crônicas, fotografias da época e notas vão se reportar a esse momento, se remetendo quase sempre aos monumentos, símbolos da riqueza experimentada pela cidade. Murilo de Meneses, na crônica intitulada Belém de outrora, invoca imagens da cidade através de um personagem que viveu sua juventude no período áureo da economia belenense. O contato estabelecido deu-se no Café da Paz, ambiente que o cronista costumava frequentar depois do cinema: 
Nessa noite, enquanto o aguaceiro caía lá fora, achando-me algo expansivo procurei puxar pela língua de meu companheiro de mesa, era um homem simpático de bom aspecto, orçando aí pelos setenta, e cujo nome peço vênia para não declinar. Fiquei com vontade de interrogar aqueles setenta anos vistoços sobre o seu passado remoto. E ele atenciosamente, com um leve sorriso de narrador requestado, principiou assim: - Ponha aí neste caderno a data, 1895. Nesse tempo o Café da Paz era o mesmo que é hoje, só se diferenciando por um jardim que existia ali onde estão os bilhares, o qual era separado das ruas por uma grade de ferro; e eu vinha aqui todas as noites, esperar os meus camaradas (Revista A Semana, de 21 de Fevereiro de 1939).

Ao caminhar pela cidade, o narrador apresentado por Murilo Meneses como um homem de bom aspecto, provavelmente pertencente à elite belenense, fazia emergir um tempo e um espaço existente em sua memória. Ao frequentar os diversos espaços de sociabilidade existentes em Belém, traz indícios do auge da borracha, em 1895, no período que ficou conhecido como Belle Époque amazônica. O local de lembrança é o Café da Paz, onde vivera sua mocidade, onde esperava seus “camaradas", ansioso por mais uma noitada. O Café da Paz emergiu na Avenida República, atual Avenida Presidente Vargas, com a Rua Carlos Gomes, e notabilizou-se como um ambiente de discussões políticas. Segundo Correa (2010, p. 304), foi muito frequentado por intelectuais e boêmios como Dejard de Mendonça, Eustáquio de Azevedo e Edgar Proença.

Nesse período, o narrador assinala que a cidade era:

Como se fosse maior. Porque, além da borracha dar um dinheirão, o câmbio era a nosso favor. Basta que lhe diga que uma libra esterlina custava 16 cruzeiros e o dólar 4. Além disso, a vida social daquele tempo tinha encanto insuspeitado pelos moços de hoje. Pelos subúrbios o carnaval era um alvoroço, com os cordões de marujo pipocando por todos os cantos; pelo São João, era a queima das fogueiras por essas ruas todas e pelo Natal eram as Pastorinhas. Sabe o que significa isso?

- Não, senhor.

- Pois eu vou dizer-lhe; significava, o cidadão que quisesse, poder dançar um dia assim, outro não, por toda a quadra natalina, durante os ensaios dos cordões. Ora, só isso assegurava a mocidade daquela época, muito maior convívio entre si. E haviase em todos os bairros. Mas quanto a este local, veja a diferença; nesse canto aí fronteiro, na qual está o Grande Hotel, era uma casa térrea ocupada pelo Café Chic; a seguir era o casarão de madeira do Politeama; onde está o Olímpia, era o Café Madrid; e dobrando além a Cruz das Almas, havia o Chat Noir, casa de diversões de demi-mond da qual era frequentador assíduo o meu amigo Jaime Abreu. Mas isso não vem ao caso do que vou lhe contar, e já se passaram 48 anos. Nesse tempo eu era um rapaz dançarino, cheio de ilusões, e atirado à vida noturna.

O senhor rememora uma Belém transformada pela riqueza advinda da borracha, notadamente traduzida pela quantidade de dinheiro que circulava na cidade e que aumentava o número de clubes para a sociabilidade das elites. Contudo, a narrativa nos apresenta mais que Belém elegante com seu Grande Hotel, com Café Chic, levando-nos a percorrer subúrbios com uma multiplicidade de 
manifestações, onde o carnaval era "um alvoroço", no qual os cidadãos podiam quase todos os dias ter momentos de diversão, estabelecendo uma maior interatividade. Logo, se torna significativo pensar que, mesmo vivendo a nostalgia da Belle Époque que vislumbrava a cultura europeia como a "verdadeira" cultura a ser seguida, as manifestações negras, como os cordões, não desapareceram, encantavam e divertiam a população belenense.

A historiadora Correa (2010, p. 310), ao estudar as manifestações culturais do período, assinala que, enquanto nas áreas centrais da cidade a elite se divertia nos clubes e cassinos, as camadas populares divertiam-se nos cordões de pássaros e carnavalescos, nos bois-bumbás ou na Praça Nazaré, onde eram realizados espetáculos sagrados e profanos. Nos bairros Umarizal e Jurunas eram tradicionais as festas de bois-bumbás e os cordões carnavalescos (CORREA, 2010, p. 307). Logo, nos bairros suburbanos, as brincadeiras ocorriam soltas, nos cordões "dos pretinhos" e nos dos marujos, que muitas vezes incomodavam a elite com suas práticas destoantes dos valores estéticos desejados (LEAL, 2005, p. 244), principalmente por seus cantos, ritmos e danças que não correspondiam à cultura pretendida, europeia. A crônica publicada por Edgar Proença ${ }^{7}$ intitulada "Minha cidade morena" traz a imagem de uma cidade que não vive mais sua "bela época":

Belém depois cresceu. Perdeu, como os moços ricos que não olham o dia de manhã, o esplendor de sua riqueza. A borracha caiu. E a minha cidade ficou pobre, mas decente. Ficou sem o fausto das suas irmãs, mas não diminuiu o aspecto e o desembaraço social. Ficou com suas mulheres, com os seus jardins, com o seu Museu, com a basílica, com as suas manhãs de sol que falam pela "boca vermelha e impassível das rosas". [...]

Amo-a com ternura e com ciúmes. Quanto mais a vejo desenvolver-se, granfinar-se mais eu evoco, com a felicidade que a hipermnésia nos proporciona, os tempos que se foram. [...]. Àquele passo pela Avenida Nazaré o meu pensamento fica preso, grudado a uma casa de azulejos, junto à antiga farmácia Galeno, hoje Bar Estrela. Foi ali que eu nasci. Meu pae sempre me dizia, apontando-a:

- Nessa casa nasceu um grande homem, vae ser tudo na vida! [...] (PROENÇA, 1941, p. 20).

A imagem da cidade, traduzida nas palavras do narrador, é de uma Belém que não vivenciou os bons tempos da borracha, logo, uma capital pobre sem "o fausto" de outrora. O que restou foram seus moradores, seus monumentos, o Museu Emílio Goeldi, a então Basílica de Nazaré. São lembranças que ficaram marcadas na memória do narrador, as recordações de uma Belém moderna,

\footnotetext{
${ }^{7}$ O escritor Edgar Campos Proença nasceu em 4 de fevereiro de 1892 em Belém, falecendo em 1972. Foi jornalista, atuando em diversos jornais e revistas, sendo inclusive diretor da revista Pará Ilustrado. Também foi radialista, bacharel em direito. Ao lado de Roberto Camelier e de Eriberto Pio fundou a Rádio Clube-PRC5, a primeira rádio a surgir no norte do país.
} 
rica e que se desejava que se perpetuasse. E apesar destes bons tempos terem passado, a cidade continuava "descente", a "granfinar-se", a cultivar os valores modernos. Assim, é possível identificar o quanto os moradores mantinham viva a memória desse passado, das igrejas, dos teatros, das ruas e avenidas, de um momento que marcou as lembranças dos que vivenciaram o período.

As narrativas apresentadas falam de um tempo em que Belém deixou de ter economia significativa em termos nacionais, quando o comércio e a indústria declinaram, consolidando a memória de uma Belém áurea no final do século XIX e início do século XX, contrapondo-se à cidade decadente das décadas de 20 e 40 . Essa visão pode ser relacionada à fase de estagnação pela qual Belém passou no pós-auge da borracha. Penteado (1968, p. 166) aponta uma situação de crise, com completa desorganização administrativa e inclusive diminuição populacional na década de 40. Apesar disso, nas memórias de muitos como Proença, Belém era bela, pelos monumentos deixados e pela exuberância natural existente. A revista Pará Ilustrado, com o título "O encanto natural da cidade" traz outros olhares sobre a cidade, não mais voltados às lembranças do passado, mas para uma Belém do presente, com sua exuberância natural, com suas praças e ruas:

Com efeito, há uma graça ruskiniana nesta natureza que nos cerca. Não precisa ser um poeta panteísta para sentir a atmosfera envolvente, o clima acolhedor da cidade. Talvez mais pela determinação da providência que por efeito natural, o rigor tropicalista é amenizado aqui por essa chuva fertilizante que refresca o ambiente e mantém o fonos verde da cidade. Da terra para o mar a perspectiva é lindíssima e alguém já lembrou que o viajante toma Belém por uma gravura animada de Rugendas. Mastros e velas emprestam à urbs um ar genovês e a vida amanhece muito cedo a beira do rio (Revista Pará Ilustrado, 14 de agosto de 1943).

Para o autor, não apresentado pela revista, Belém é representada diferentemente das imagens de Meneses e Proença, sendo uma cidade pitoresca, com enfoque para os elementos naturais como principal atração, a chuva "que refresca o ambiente", o amanhecer na "beira do rio". Focaliza elementos do presente não mais presos a uma imagem do passado, dos bons tempos da borracha. Logo, o ponto central de sua narrativa é a exuberância natural, a água do rio, a água da chuva que ameniza o calor e fertiliza o solo tornando a cidade mais verde e bela. A narrativa prossegue:

Por outro lado, essa arborização abundante dá a cidade uma feição peculiar. São as mangueiras bailarinas de Eneida, no braço vegetal de suas ramagens.

Os parques e as praças de nossa terra merecem ser citados pela extraordinária beleza que possuem. São amplos, agradáveis a vista, convidando a um passeio a suas áreas (Revista Pará Ilustrado, 14 de agosto de 1943). 
Para o narrador, a presença de árvores, das mangueiras, proporciona uma atmosfera peculiar à cidade, diferenciando-a de qualquer outra capital, ressaltando a beleza natural como elemento de distinção. Entretanto, pontua a existência de outros elementos que a tornam bela, a presença de parques e praças, trazendo uma imagem da cidade constituída de espaços de sociabilidade, de lazer, uma cidade bela e moderna. Eneida, provavelmente Eneida de Moraes, escritora paraense que escrevia crônicas e poemas sobre a cidade, também é destaque no comentário, principalmente pela infância vivida em Belém, antes de mudar para o Rio de Janeiro ${ }^{8}$. A tentativa de difundir essa imagem da cidade exuberante, constituída de beleza e modernidade, vem sendo proposta desde o século XX. Antônio Lemos, durante sua intendência, permitiu a edição do Álbum de Belém, no intuito de desconstruir a imagem de cidade formada por pessoas incultas, vivendo em precárias habitações (SARGES, 2002, p. 107).

Posteriormente, segundo Correa (2010, p. 33), na interventoria de José Gama Malcher, foi editado o Álbum do Pará, sendo publicadas fotografias da cidade em revistas, na tentativa de construir uma imagem de modernidade, elegância e cultura. Não por acaso, revistas como o Pará Ilustrado, em circulação na década de 40, trazem em suas páginas inúmeras fotografias apresentando praças ajardinadas, largas avenidas, o Bosque Rodrigues Alves, a Igreja de Nossa Senhora de Nazaré, convidando os cidadãos a frequentarem esses espaços de lazer. E, mais ainda, destacando a importância desses espaços para o engrandecimento da cidade.

Nessa cidade de múltiplos olhares era possível identificar diversos espaços de sociabilidade, como Praça da República, Praça Castilho França, Praça Batista Campos, Bosque Rodrigues Alves, avenidas e ruas como a João Alfredo - conhecida como a Rua do comércio, do dinheiro, do bom chapéu (REVISTA A SEMANA, 1938). Havia espaços privados, a exemplo dos clubes futebolísticos: Clube do Remo, Clube do Payssandú, Clube da Tuna Luso Brasileira; os hotéis: Palace Hotel, Palace Cassino, dentre outros existente na capital. Esses espaços foram, durante muito tempo, espaços de folia. A cidade era marcada por várias manifestações culturais de cunho religioso ou profano, festas que ocorriam em diversos pontos da cidade, integrando o calendário festivo de Belém, como festa de São João, Nossa Senhora de Nazaré e as festas carnavalescas. Estas, por sinal, recebiam grande atenção dos meios de comunicação locais pela sua relevância, tanto em âmbito nacional quanto local,

\footnotetext{
${ }^{8}$ Eneida de Moraes nasceu em Belém em 1903, quando criança teve que ir para o Rio de Janeiro estudar, retornando em 1916 e permanecendo até 1930, período em que escreveu várias crônicas e poemas para as revistas belenenses. Durante a década de 30 foi presa por se envolver no Movimento Constitucionalista de São Paulo (1932) e em 1936 pelo enfrentamento nas lutas políticas contra o governo de Getúlio Vargas. Retornou à capital em 1945. Escreveu as obras Quarteirão, quando ainda estava no cárcere, em 1953 escreveu sua obra clássica História do carnaval, escreveu Aruanda em 1957 e Banho de cheiro em 1963.
} 
e os jornais do período dedicavam um espaço importante de suas edições para a divulgação desses eventos culturais e festivos.

Os jornais do período indicavam mais do que simples registro da ordem vigente, pois atuavam como construtores dessa ordem. Observando as notícias, percebemos como a imprensa criava uma espécie de dicotomização do espaço urbano e, em especial, do espaço festivo. Não por acaso, a festa representava a divisão entre os espaços de elite, caracterizados pelos clubes sociais, e os da população suburbana, que correspondiam aos assustados ${ }^{9}$ e blocos carnavalescos.

Era possível observar esses territórios diferenciados se percorrêssemos as ruas da cidade de Belém na década de 40, mais especificamente nos dias de carnaval, quando encontraríamos uma multiplicidade de opções de folia carnavalesca, diversos lugares onde, dependendo do nível socioeconômico, o folião poderia ou não participar do carnaval. Na região central da cidade, principalmente no bairro Nazaré e na Praça da República, existia uma variedade de locais de cultura e lazer. Esses espaços já haviam se estabelecido desde a Belle Époque como locais de entretenimento, sendo possível ir à Praça da República, ao Teatro da Paz, ao Cine Olímpia, ao Grande Hotel e ao Café da Paz. Nas décadas de 30 e 40, os principais clubes carnavalescos também habitavam essa região. Nessas regiões se concentravam os principais ambientes de sociabilidade das elites frequentadoras dos clubes carnavalescos, como Assembleia Paraense, Sport Clube, Tuna, Clube do Remo, Paysandu, Palace Cassino. Alguns desses clubes se fazem presentes desde o final do século XIX, como é o caso da Assembleia Paraense e do Sport Clube (CORREA, 2010, p. 309), que desde então eram clubes prediletos das famílias da elite belenense, onde se reuniam para divertimentos nos bailes de carnaval.

Os mais bem estabelecidos frequentavam principalmente e, não exclusivamente, clubes como o da Assembleia Paraense. Fundada em 27 de dezembro de 1915, era o ambiente predileto da mais alta expressão aristocrática da cidade. Desde sua fundação mereceu a preferência dos mais altos representantes da coletividade, passando suas festas a constituir o que de mais elegante podia ser exibido (CRUZ, 1973, p. 427). Ou então, participavam do Clube do Remo, uma das mais antigas associações desportivas e sociais de Belém, criado com o objetivo de contribuir para a vida recreativa da cidade. Ou ainda, o Paysandu Sport Club, fundado em 2 de fevereiro de 1914, como uma ramificação do Norte Club conhecido como Time Negra ${ }^{10}$, clube que realizava as mais belas festas

\footnotetext{
${ }^{9}$ Os assustados eram festas carnavalescas que ocorriam em vários bairros da cidade, sendo caracterizados pela imprensa belenense como festa do subúrbio, das camadas menos privilegiadas da sociedade.

${ }^{10} \mathrm{O}$ surgimento do Paysandu Sport Club foi ocasionado pelo inconformismo reinante entre componentes do Norte Club, também chamado de Time Negra, contra a diretoria da Liga Paraense de Football, que considerou improcedente recurso interposto, através do qual pediam, por ocasião de diversas irregularidades, a anulação da partida Norte Clube 1 x Guarany 1, realizada em 15 de novembro de 1913. Esse resultado deu o título ao atual Clube do Remo. A decisão não agradou aos integrantes do Norte Club, que resolveram fundar uma nova agremiação. Hugo Manuel de Abreu Leão, que jogava no
} 
carnavalescas da cidade, reunindo entre seus sócios a elite belenense que se preparava para festejar, nos amplos salões da cidade, a noite carnavalesca do Paysandu.

Se em nenhum desses grupos pretendesse foliar, poderia percorrer as ruas de Belém e encontraria, na Rua Nova de Santana, atual Manoel Barata, esquina com a Travessa Campo Sales, o clube Tuna Luso Brasileira, conhecido como Tuna, um dos clubes criados nos primeiros anos do século XX. Fundado em $1^{\circ}$ de janeiro de 1903, o clube, na ocasião, chamava-se Tuna Luso Caixeral, Tuna no sentido de agrupamento de jovens alegres, e Caixeral em virtude da função que exerciam no comércio paraense de caixeiros. Este foi criado no sentido de congregar portugueses que viviam em Belém, sendo espaço cultural onde pudessem compartilhar músicas, danças e arte. A primeira diretoria tinha como presidente Manuel Nunes da Silva, secretário Manoel Augusto Correia e Antônio Lobo.

Grande parte dos anúncios de bailes carnavalescos presentes nos periódicos em circulação na década de 1940 era de eventos organizados pelos clubes sociais, que propagandeavam suas festas e todos os preparativos da folia, no intuito de mobilizar a elite belenense para suas comemorações. Entretanto, os anúncios possibilitaram-nos ir além da simples propaganda, permitindo perceber a construção de um referencial identitário pelas elites que buscavam reunir-se num único espaço, aglomerando "os seus", diferenciando-se do que para a elite do período era o não carnaval - a bagunça -, por isso a preocupação com a ornamentação, com o luxo, com a beleza. Esses são elementos que nos enveredam a compreender o carnaval realizado pelos clubes.

$\mathrm{Na}$ contramão do que se propunham as festas carnavalescas realizadas nos clubes das elites, as festas populares ocorriam em outros espaços como Jurunas ${ }^{11}$, Umarizal, Guamá ${ }^{12}$, com outros valores e significados, uma vez que a festa era confraternização, exposição de alegrias e tristezas,

\footnotetext{
Norte Club, era líder do movimento destinado à fundação. Consultar: Revista Paysandu Sport Club - Campeão dos Campeões, p.14.

${ }^{11} \mathrm{O}$ bairro Jurunas, conhecido hoje por sua expressividade cultural, tem como etimologia do termo, segundo Rodrigues (2006), uma palavra de origem toponímica em um grupo indígena de língua yudjá. Os Jurunas são conhecidos através de notícias históricas desde o século XVII, quando habitavam as zonas mais próximas da foz do Amazonas, pela qual foram subindo até chegar ao rio Xingu, posteriormente ao Alto Xingu (século XX), em terras transformadas no Parque Indígena do Xingu (1960), onde disputaram com outros grupos, novos e antigos na região, o espaço de sobrevivência e manutenção de sua forma de existência. Consultar: RODRIGUES, Carmem Isabel. Vem do Bairro do Jurunas: sociabilidade e construção de identidades entre ribeirinhos em Belém-PA. Tese (Doutorado em Antropologia) - Universidade Federal de Pernambuco (UFPE), Pernambuco, 2006.

${ }^{12}$ De acordo com Júnior (2009) a origem do bairro se deu a partir de duas direções, uma primeira ocupação desencadeada no início do século XX, a partir do bairro de São Braz, e outra intensificada na década de 1950, proveniente do Rio Guamá. Essa ocupação realizada pelas margens do Rio Guamá ocorreu com a presença marcante de pessoas oriundas das regiões do Rio Guamá, do Rio Acará e do Baixo Tocantins. Por esse motivo o bairro adquiriu esta denominação, Guamá. Consultar: DIAS JÚNIOR, José do Espírito Santo. Cultura Popular no Guamá: um estudo sobre o boi-bumbá e outras práticas culturais em um bairro da periferia de Belém. Dissertação (Mestrado em História) - Universidade Federal do Pará (UFPA), Belém, 2009.
} 
manifestação de ritmos e de corpos, especialmente nos dias dedicados ao momo ${ }^{13}$, em locais onde se estabeleciam fábricas, comércio, as usinas de Belém, pertencentes ao cotidiano das classes populares, espaços em que viviam e trabalhavam. Nesses bairros - Cidade Velha, Campina e Reduto, Jurunas, Umarizal, Pedreira e Guamá -, os populares tinham modos de vida pautados por outros hábitos. No bairro Reduto, por exemplo, se estabeleceu grande parte das fábricas existentes em Belém nas primeiras décadas do século XX. Segundo Souza (2006, p. 93), aproximadamente 20 estabelecimentos relacionavam-se a setores como bebidas, alimentos, calçados, construção civil, produtos de limpeza e higiene, levantamento de edificações fabris e outros, existentes no bairro na segunda metade do século XX. Dentre esses estabelecimentos destacam-se a Sapataria Boa Fama, a fábrica Perseverança e a Phebo, dentre outras que compunham o bairro consolidando-o como operário. Nesse bairro a principal mão de obra advinha de Jurunas e Umarizal, cujos moradores se deslocavam todos os dias para trabalhar, ou para onde iam em busca de trabalho. Pela imprensa belenense eram considerados bairros suburbanos, principalmente Jurunas, Umarizal, Pedreira e Guamá, que exibiam residências simples construídas com madeira e cobertura de palmeira, muitas dessas erguidas em áreas alagadiças. Acerca disso Isabel Rodrigues discute que Jurunas se compôs sobre terreno alagadiço cortado por braços de igarapés, ligados ao rio Guamá, transformados em valas sobre as quais foram construídas casas e pontes de madeira.

Esses bairros são historicamente marcados por manifestações culturais desde meados do século XIX, pelo menos, principalmente Umarizal e Jurunas. Era nestas imediações que a cultura popular se manifestava amplamente, especialmente no carnaval, um dos momentos nos quais a cultura popular ganhava espaço ${ }^{14}$, inclusive na mídia, ainda que fosse recorrente nas páginas policiais. Acerca desses bairros, Campos Ribeiro traz lembranças das primeiras décadas do século XX, principalmente das áreas suburbanas como Umarizal, onde passou parte de sua vida. Através de suas lembranças é

\footnotetext{
${ }^{13}$ Discutiremos melhor a festa dos populares, seus espaços, valores e significados no tópico Festa de Assustado.

${ }^{14}$ Nesse sentido, as análises de Bakhtin auxiliam na compreensão da cultura popular, a cultura cômica popular na Idade Média e no Renascimento. As festas constituem uma "forma primordial" e marcante da humanidade, não apenas pelo descanso da labuta diária que nestes eventos são temporariamente desfrutados, mas principalmente por elas exprimirem uma concepção de mundo. De acordo com o autor, era no carnaval e em outras festas públicas que o povo penetrava em um "reino utópico da universalidade, liberdade, igualdade e abundância". As festas como o carnaval possibilitavam a eliminação das hierarquias permitindo outro tipo de comunicação entre os indivíduos, com um vocabulário próprio e gestual, sem restrições, o que fazia com que as pessoas se libertassem de certos códigos de etiqueta e de moral ${ }^{14}$, em contraposição à festa oficial que não permitia ao povo mostrar sua verdadeira face. Por isso, o carnaval é apresentado pelo autor como algo central na vida do homem medieval. Nesse sentido, as abordagens de Bakhtin contribuíram para pensar acerca do carnaval belenense, nos permitindo visualizar novos olhares sobre espaços dominados pela cultura popular, as estratégias, as resistências, o riso festivo popular dos grupos que cotidianamente eram criticados. Logo, buscar entender as festas carnavalescas realizadas pelos populares em Belém é compreender outra dimensão da festa, diferente da apresentada pelas elites belenenses, com outros códigos, sentidos e valores, perpassando desde o território ao significado da festa.
} 
possível perceber circunscrições do bairro, do Umarizal da sua meninice, da adolescência onde guarda na memória, em amareladas fotografias, muitas quase desmaiadas todas, porém, marcando gratas, divertidas e até saudosas, agridoces lembranças (RODRIGUES, 2006, p. 35).

Segundo este autor, "entre as manifestações da alegria popular em nossa terra nenhuma tanto apaixonava a alma do povo quanto as festas juninas" (RIBEIRO, 2005, p. 99). Estas contagiavam um grande número de participantes de vários bairros da cidade organizados em grupos, formando um boi-bumbá. Cada bairro suburbano possuía seu bumbá. A Cidade Velha, o Umarizal e o Jurunas eram bairros onde existiam os grupos.

Os traços do bairro do Umarizal, assim como do Jurunas com suas múltiplas manifestações populares apresentadas pelo autor, nos levam a perceber um subúrbio ativo que, desde as primeiras décadas do século XX, era o principal palco dos movimentos populares de Belém, constituindo espaço de entretenimento da população, principalmente da população pobre e negra, que formavam esses bairros e que viam nos bois-bumbás meios de diversão. Na década de 40 essas localidades continuavam sendo centros radiadores de cultura, neles organizando-se os principais assustados e blocos carnavalescos, formando laços de sociabilidade e folia das classes populares. Nesses bairros foi possível identificar, entre os anos em estudo, inúmeros blocos carnavalescos, assim como um número representativo de assustados, realizados em vários pontos da cidade.

Esse bairro era constituído de muitas agremiações carnavalescas, sendo um dos bairros mais movimentados nos dias de folia. Além dessas agremiações era possível encontrar um número significativo de associações esportivas, compondo uma rede de sociabilidade do bairro, entretanto era constantemente desqualificado pelas mídias como um local violento ${ }^{15}$, perigoso, ambiente de gangues que atormentavam os bairros vizinhos, sendo a violência parte de seu cotidiano. Essa desqualificação se intensificou no período do Estado Novo em Belém, principalmente no caso dos bairros suburbanos, onde as referências a vadiagem, molecagem e diversas práticas populares eram utilizadas pejorativamente, sendo as populações por isso combatidas, disciplinadas, em nome do bem-estar da sociedade. Luiz Augusto Leal (2011, p. 72) nos apresenta as diversas prisões realizadas contra a falta de moralização social de indivíduos ou grupos pertencentes a esses bairros, incluindo práticas de jogar futebol de rua e jogar baralho em festejos públicos realizados pela cidade, como o carnaval e as festas juninas.

\footnotetext{
${ }^{15}$ ESBOFETEOU A MULHER: "Encontra-se detido no comissariado do Jurunas, onde ficará até as 11 horas de hoje, Francisco de Souza Pinheiro, Paraense, Pardo, Solteiro de 19 anos, analfabeto, residente à rua da Conceição. Sem motivo justificado aplicou violenta bofetada em Ligia de Oliveira Santos, residente àquela mesma rua. Folha Vespertina, 9 de fevereiro de 1942, p. 1.
} 
No bairro do Jurunas o carnaval era uma das festas mais expressivas; entre as folias existentes nesse bairro havia também a presença de clubes carnavalescos, que recebiam um número significativo de brincantes para comemorar o carnaval, entre os quais se destacavam os clubes São Domingos Sport Club, localizado na Avenida Roberto Camelier, número 816 (Ata de Fundação ao São Domingos Sport Club, p. 5) e O Imperial, localizado na Rua Conceição, número 858, no Jurunas, tendo sido comprado o terreno em $1939^{16}$. Além desses, evidenciamos muitos blocos de carnaval e assustados que povoavam o ambiente carnavalesco do bairro.

Como salientamos, Belém nesse momento era constituída por muitos bairros, caracterizavase como uma cidade crescente em termos populacionais, crescimento já experimentado na virada do século XIX para o XX, e que tinha em suas múltiplas regiões diversos modos de frequentar o carnaval, em clubes da Avenida Nazaré, aos arredores da Praça da República, ou nas brincadeiras de rua do Jurunas e do Umarizal.

\section{Referências}

ARANTES, Antonio Augusto. Paisagens paulistanas: transformações do espaço público. Campinas:

Editora da Unicamp; São Paulo: Imprensa Oficial, 1999.

CORREA, Ângela Tereza de Oliveira. Belém do Pará, palco de manifestações culturais no início do século XX. In: SIMONIAN, Ligia Terezinha Lopes (org.). Belém do Pará: História, cultura e sociedade. Belém: UFPA, 2010.

CRUZ, Ernesto. História de Belém. Belém: UFPA, 1973.

FERRARA, Lucrécia D’Aléssio. As máscaras da cidade. In: Olhar periférico: informação, linguagem, percepção ambiental. São Paulo: EDUSP, 1999.

FLÓRIO, Marcelo; AVELINO, Yvone Dias. Polifonias da cidade. São Paulo: Editora Escrever, 2009.

LEAL, Luiz Augusto Pinheiro. Capoeira e Boi-Bumbá: territórios e lutas da cultura afro-amazônica em Belém (1889-1906). Revista Afro-Ásia, n. 32. Universidade Federal da Bahia, 2005.

\footnotetext{
${ }^{16}$ Ver Revista GOL, p. 23.
} 
LE GOFF, Jacques. Por amor às cidades: conversações com Jean Lebrun. São Paulo: UNESP, 1988.

PENTEADO, Antônio Rocha. Belém do Pará: estudo de geografia urbana. v. 2. Belém: Universidade Federal do Pará, 1968.

PROENÇA, Edgar. Gravetos. São Paulo: Anchieta, 1941.

OLIVEIRA, Alfredo. Carnaval paraense. Belém: Secult, 2006.

SARGES, Maria de Nazaré. Belém, a urbe das riquezas. In: SARGES, Maria de Nazaré. Belém. Riquezas produzindo a Belle Époque (1870-1912). Belém: Paka-Tatu, 2002.

RIBEIRO, José Sampaio de Campos. Gostosa Belém de outrora. Belém: Secult, 2005. 